\title{
ECOLOGIA DA POLINIZAÇÃO DE IPOMOEA ASARIFOLIA (DERS.) ROEM. \& SCHULT. (CONVOLVULACEAE) NA REGIÃO SEMI-ÁRIDA DE PERNAMBUCO
}

\author{
Lúcia Helena Piedade Kiill ${ }^{1}$ \\ Neusa Taroda Ranga ${ }^{2}$
}

Recebido em 20/06/2002. Aceito em 28/11/2002

\begin{abstract}
RESUMO - (Ecologia da polinização de Ipomoea asarifolia (Ders.) Roem. \& Schult. (Convolvulaceae) na região semi-árida de Pernambuco). O presente trabalho foi desenvolvido no período de março/1995 a julho/1997, com o objetivo de estudar aspectos da fenologia, polinização e reprodução de Ipomoea asarifolia, na Fazenda Catalunha, Santa Maria da Boa Vista, PE. I. asarifolia é uma liana perene, com hábito exclusivamente rasteiro e floração registrada no período de março a outubro, caracterizada como do tipo cornucópia. As flores estão reunidas em cimeiras, são infundibuliformes, de cor rosa com as mesopétalas magenta, que funcionam como guias de néctar. A antese é diurna (5:30 e 6:00h) e a duração das flores é de aproximadamente seis horas. A quantidade de néctar secretada por flor é inferior a 1 $\mu 1$. Abelhas Megachilidae e Apidae foram os principais visitantes desta Convolvulaceae. Liturge huberi Ducke foi considerada polinizador efetivo e Acamptopoeum prinii Holm. e Diadasina riparia Ducke polinizadores ocasionais. Quanto ao sistema de reprodução, I. asarifolia é autoincompatível, produzindo frutos e sementes viáveis somente após polinização cruzada. Os testes de crescimento de tubo polínico mostraram que, após 10 horas, há tubos polínicos na micrópila de óvulos autopolinizados e daqueles submetidos à polinização cruzada, sugerindo que se trata de um sistema de incompatibilidade tardia. Os testes de germinação mostraram que somente as sementes obtidas em condições naturais $(93,3 \%)$ e nos experimentos de polinização cruzada (100\%) foram viáveis, reforçando os dados obtidos no sistema de reprodução.
\end{abstract}

Palavras-chave - biologia floral, sistema de reprodução, Ipomoea asarifolia, Convolvulaceae, invasora

\begin{abstract}
Pollination ecology of Ipomoea asarifolia (Ders.) Roem. \& Schult. (Convolvulaceae) in the semiarid area of Pernambuco). The present work was carried out during March/1995 to July/1997, to study aspects of the phenology, pollination and reproduction of Ipomoea asarifolia growing at Fazenda Catalunha, Santa Maria da Boa Vista, PE. I. asarifolia is a perennial creeping liana with floration registered in the period of March to October, characterized as a cornucopian pattern of flowering. The flowers are gathered in cymes, with a pink funnel-like corolla with magenta mesopetals working as nectar guides. The anthesis is diurnal (05:30 - 06:00 h) and the flowers lasting for approximately six hours. The amount of nectar secreted by flower is less then $1 \mu$ l. Bees Megachilidae and Apidae were the main visitors of this Convolvulaceae. Liturge huberi Ducke was considered as effective pollinatior, and Acamptopoeum prinii Holm. and Diadasina riparia Ducke as occasional. Ipomoea asarifolia is self-incompatible, producing fruits and viable seeds only after crossed pollination. However the tests of pollen
\end{abstract}

1 Embrapa Semi-Árido, BR 428, Km 152, Zona rural, C. Postal 23, CEP 56302-970, Petrolina, PE, Brasil (kiill@cpatsa.embrapa.br)

2 Departamento de Botânica, IBILCE, UNESP, C. Postal 136, CEP 15054-020, São José do Rio Preto, SP, Brasil 
tube growth showed that 10 hours after pollination, pollen tubes reached the micropile of both self- and crosspollinated ovules, suggesting a late acting self-incompatibility system. The germination tests showed that only the seeds obtained in natural conditions $(93,3 \%)$ and from cross-pollination experiment $(100 \%)$ were viable, reinforcing the data obtained in the reproduction system.

Key words - floral biology, reproductive system, Ipomoea asarifolia, Convolvulaceae, weed

\section{Introdução}

Diversas espécies do gênero Ipomoea estão incluídas entre as plantas daninhas que ocorrem com frequiência em áreas cultivadas (Blanco 1978; Groth 1991; Kissman \& Groth 1992). Entre elas encontra-se Ipomoea asarifolia (Ders.) Roem. \& Schult., popularmente conhecida como salsa, batata-salsa, salsa-brava. Esta espécie é encontrada em várias culturas e em margens de lagoas e praias marítimas, de preferência em solos arenosos (Blanco 1978). Segundo Austin \& Cavalcanti (1982) e Simão-Bianchini (com. pess.), esta Convolvulaceae é pantropical, com ampla ocorrência no Brasil.

A biologia floral e o sistema de reprodução de espécies de Ipomoea que apresentam características de plantas invasoras vêm sendo estudados com o objetivo de revelar os principais aspectos em relação à forma de reprodução e biologia da polinização, que são essenciais para a elaboração de programas de controle (Blanco 1978). Entre os diversos trabalhos, pode-se citar Machado \& Sazima (1987); MaimoniRodella et al. (1982); Maimoni-Rodella (1991); Maimoni-Rodella \& Rodella (1992) e Fidalgo (1997). O presente trabalho foi desenvolvido com o objetivo de estudar a fenologia, os mecanismos de polinização e o sistema de reprodução de Ipomoea asarifolia na região semi-árida de Pernambuco, contribuindo com informações sobre a biologia floral e a reprodução desta espécie, considerada como planta invasora de cultura, principalmente em áreas de fruticultura irrigada.

\section{Material e métodos}

Este trabalho foi desenvolvido na Fazenda Catalunha $\left(8^{\circ} 55^{\prime} \mathrm{S}\right.$ e $\left.39^{\circ} 54^{\prime} \mathrm{W}\right)$, município de Santa Maria da Boa Vista, Pernambuco. A vegetação dominante na área é do tipo caatinga hiperxerófila (Andrade-Lima 1989), com clima que se enquadra no tipo Bswh' da classificação de Köppen, definido como semi-árido (chuva anual inferior a $750 \mathrm{~mm}$ ), sem excesso hídrico. A estação chuvosa ocorre no período de novembro a abril, e a estação seca ocorre no período de maio a outubro. Os dados climáticos do período de 1995 a 1997 estão na Fig. 1 .

As observações de campo foram desenvolvidas no intervalo de março/1995 a julho/1997, no período entre 5:00 e 12:00h, envolvendo 12 indivíduos de Ipomoea asarifolia, aleatoriamente marcados em uma área de 500ha. Para o estudo da fenologia, observações semanais foram feitas ao longo de todo o período de observação. Quanto à morfologia, 20 flores foram mensuradas com auxílio de paquímetro, para verificar o comprimento e diâmetro da corola, bem como a posição e tamanho das estruturas reprodutivas. Observações da biologia floral foram feitas ao longo de toda floração, totalizando 240 horas. Para verificar a viabilidade dos grãos de pólen, lâminas foram preparadas com Carmin Acético 1,2\% (Radford et al. 1974). Para isso, botões em pré-antese, de três indivíduos, foram coletados. Cinco lâminas foram preparadas utilizando-se as cinco anteras, sendo que em cada uma foram amostrados 100 grãos de pólen, totalizando 500 grãos. A receptividade do estigma foi testada com Sudam III (Johansen 1940). Os visitantes foram observados ao longo 


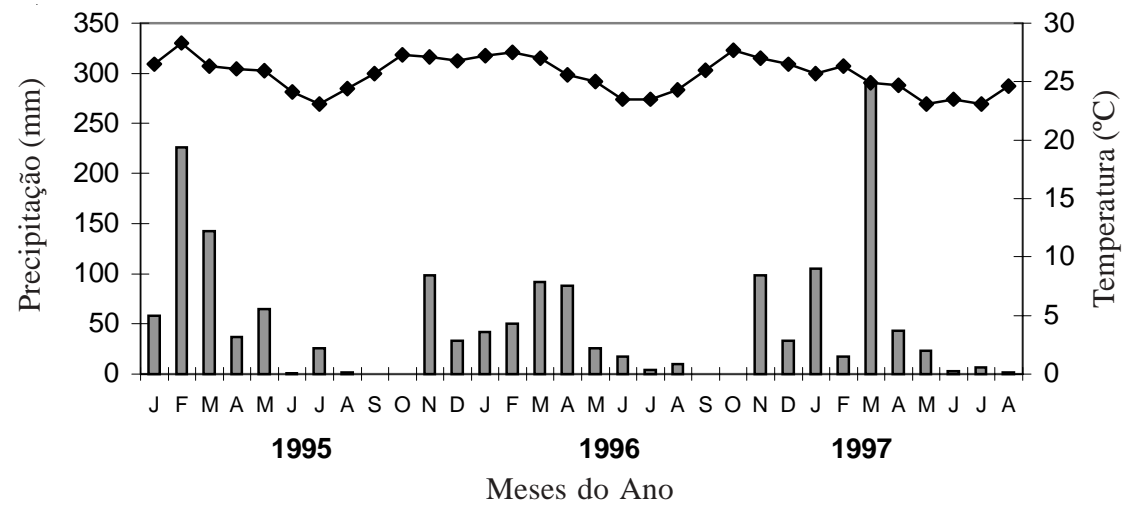

Figura 1. Dados climáticos da região de Petrolina, no período de janeiro/1995 a agosto/1997. (Fonte: Centro de Pesquisa do Trópico do Semi-árido - Embrapa Semi-Árido).

do período de floração, sendo anotadas a frequiência, duração e horário de suas visitas, bem como o comportamento dos visitantes mais freqüentes. Para cada seção de observação dos visitantes florais (ex. 7:00-8:00h), cinco repetições em dias não consecutivos foram feitas, totalizando 30 horas de observação. Para verificar diferenças de comportamento em relação à cor da flor visitada, três seções entre 8:00 e 10:00 horas foram feitas, em indivíduos com flores de cores diferentes.

Para determinar a estratégia reprodutiva da espécie, flores foram submetidas aos experimentos de autopolinização espontânea e manual, agamospermia, e polinização cruzada (Dafni 1992), bem como observadas em condições naturais. Para cada tratamento foram utilizadas 30 flores previamente ensacadas e emasculadas, quando necessário. O pólen usado nas polinizações manuais foi obtido de flores ensacadas. Testes de crescimento de tubo polínico foram feitos em flores previamente submetidas a autopolinizações manuais e polinizações cruzadas em intervalos de tempo regulares $(5,10,24$ e $48 \mathrm{~h})$, onde o gineceu foi submetido à técnica de coloração segundo Martin (1959). Sementes obtidas em condições naturais, bem como as obtidas nos experimentos de polinização foram usadas nos testes de germinação, onde as mesmas foram acondicio- nadas em placas de Petri e umedecidas com água destilada. Materiais-testemunho foram depositados nos Herbários da Unicamp (UEC 90.767) e da UNESP de São José do Rio Preto (SJRP 10.251).

\section{Resultados e discussão}

Ipomoea asarifolia é uma liana perene de hábito rasteiro, que ocorre espontaneamente em vários pontos da Fazenda Catalunha, principalmente em áreas abertas ou nas bordas da área estudada. A fenofase de brotamento ocorreu praticamente ao longo de todo o ano, atingindo o pico no período março/abril. A floração ocorreu de março a outubro, sendo o mês de maio considerado como pico desta fenofase (Fig. 2). Por apresentar produção diária de muitas flores por planta, ao longo de várias semanas, com elevada sincronia intraespecífica, esta espécie se enquadra no padrão de floração do tipo cornucópia (Gentry 1974). Esta produção diária de muitas flores por indivíduo, juntamente com a coloração vistosa da corola, tornava os indivíduos desta espécie bem atrativos, o que, consequientemente, contribuiu para a atração do polinizador à longa distância (Kevan 1978). A frutificação e a senescência das folhas ocorreram principalmente ao longo da estação seca (Fig. 2) e estão diretamente 


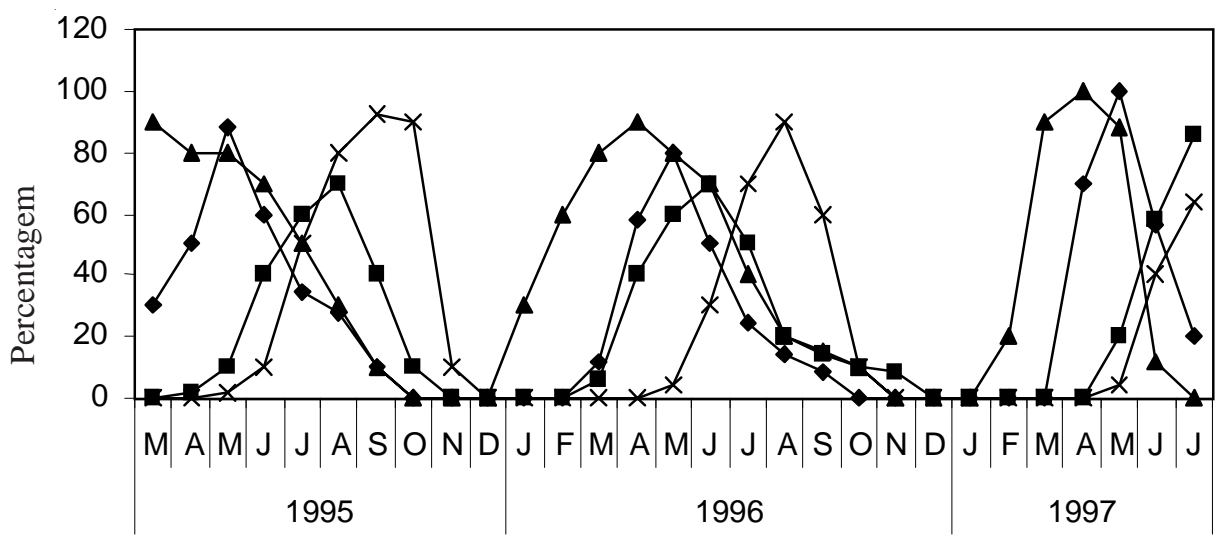

Meses do ano

Figura 2. Fenograma de Ipomoea asarifolia na Fazenda Catalunha, durante o período de março/1995 a julho/1997. $\longrightarrow$ Floração; —— Frutificação;—ム—Brotamento; * Senescência.

associadas com a ausência de precipitação, coincidindo com o observado para outras convolvuláceas da região (Piedade 1998), bem como para outras espécies da caatinga (Machado et al. 1997).

As flores desta Convolvulaceae encontram-se reunidas em inflorescências com cinco a 15 botões $(n=15)$, onde ocorreu a antese de duas a três flores por dia, por inflorescência. As flores são infundibuliformes (em média $13 \mathrm{~mm}$ diâm. e $84 \mathrm{~mm}$ compr., Fig. 3), inodoras e geralmente permanecem em posição inclinada, ou seja formando um ângulo superior a $90^{\circ} \mathrm{em}$ relação ao eixo da inflorescência. A corola é predominantemente de cor rosa, com o interior do tubo e região das mesopétalas de coloração magenta, que funcionam como guias de néctar. Este padrão de coloração foi encontrado em nove indivíduos ( $75 \%$ da população). Nos outros três indivíduos (25\%) observou-se que há variação da coloração da corola, desde indivíduos com corola branca com mesopétalas rosa (1), até indivíduos com flores totalmente brancas (2). $\mathrm{O}$ androceu é formado por cinco estames epipétalos, heterodínamos, com filetes que apresentam base mais dilatada e pilosa (tricomas), formando cinco canais de acesso ao local de deposição do néctar, na base do tubo da corola. As anteras são bitecas (Fig. 3), com deiscência rimosa. $\mathrm{O}$ gineceu é formado por um ovário súpero, tetraovulado, estiletes fundidos e estigmas bilobados, e fica envolto pelos estames, posicionado no mesmo nível ou abaixo das

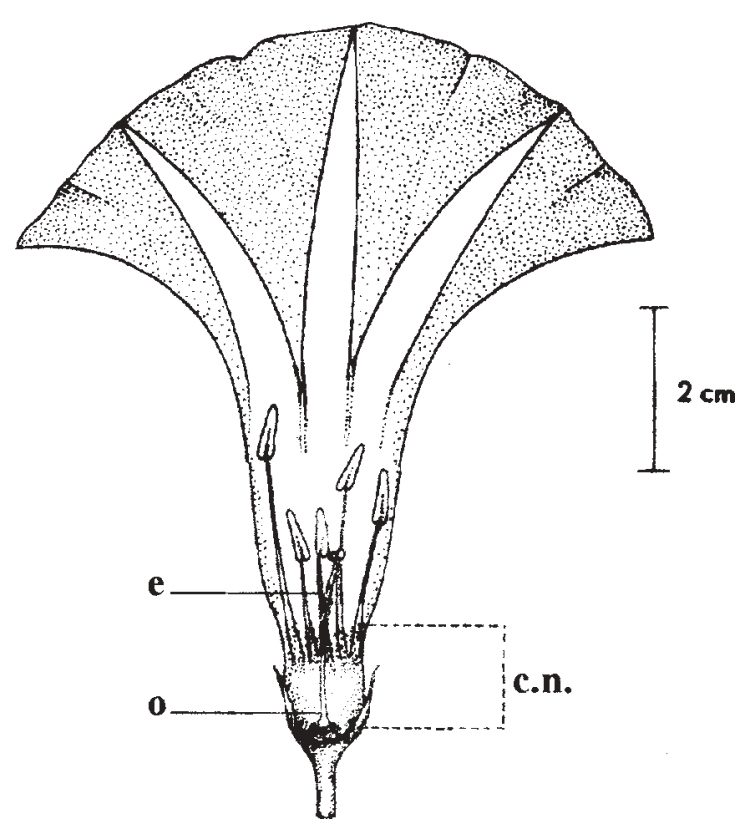

Figura 3. Esquema da flor de Ipomoea asarifolia em corte longitudinal não mediano. Notar o estreitamento da base da corola. e - estilete, o - ovário, c.n. - câmara nectarífera. 
anteras, ocupando a porção central do tubo da corola. A proximidade do estigma e das anteras facilita a autopolinização, o que poderia levar a espécie a desenvolver mecanismos para evitar a autofecundação. O nectário se apresenta na forma de um disco hipógino e a câmara nectarífera apresenta cerca de $8,0 \mathrm{~mm}$ alt. (Fig. 3). Nectários extra-florais foram encontrados na base das sépalas do cálice e no pedicelo, porém ao longo das observações não foi encontrado nenhum sinal de que os mesmos fossem funcionais, uma vez que não foi observado néctar nessas estruturas.

A antese das flores é diurna (5:30 e 6:00h), caracterizada pelo lento afastamento das bordas da corola, que se destorcem. Nesta fase os grãos de pólen estão disponíveis nas anteras e apresentam alta viabilidade $(94,4 \%)$. O estigma está receptivo e há acúmulo de pequenas quantidades de néctar (em média, inferior a $1 \mu \mathrm{l}$ ) na base da corola. As flores permanecem sem modificações até as 11:00h, quando então inicia o processo de senescência floral, caracterizado pelo murchamento das bordas da corola, fechando a entrada do tubo. A duração da flor é de aproximadamente seis horas e, cerca de 24 horas após a antese, ocorre a queda dos elementos florais. Por apresentar atributos florais como antese diurna, corola de cores vivas e contrastantes, guias de néctar, plataforma de pouso, e néctar abrigado na base da corola, Ipomoea asarifolia pode ser classificada como melitófila (Faegri \& van der Pijl 1980).
As flores de Ipomoea asarifolia foram visitadas por abelhas Megachilidae, Andrenidae e Apidae (Tab. 1). Entre elas, Liturge huberi foi a mais abundante, sendo responsável por $59 \%$ do total de visitas. Acamptopoeum prinii e Diadasina riparia apresentam freqüências de visitas bem menores, em torno de $20 \%$. Com relação ao horário de visita, L. huberi foi observada em todos os horários, atingindo pico de visita entre 9:00 e 10:00h. Já $A$. prinii e $D$. riparia concentraram suas visitas de 8:00 às 11:00h.

Quanto ao comportamento de visita e o recurso floral forrageado, as três abelhas apresentaram comportamento semelhante. Liturge huberi pousava na fauce da corola, dirigia-se para o interior do tubo, curvava o corpo ao redor das estruturas reprodutivas e, com o auxílio das pernas e das peças bucais, coletava pólen. Na ocasião, a abelha contatava anteras e o estigma com a região ventral do corpo, onde o pólen era depositado, caracterizando a polinização esternotríbica. Após a coleta, a abelha recuava até a fauce da corola, de onde levantava vôo. $A$. prinii e $D$. riparia apresentaram comportamento de coleta de pólen semelhante ao descrito para L. huberi, diferindo somente no posicionamento intrafloral. Estas abelhas pousavam sobre os estames mais longos, onde iniciavam a coleta de pólen, dirigindo-se posteriormente até os estames intermediários e curtos.

Durante as observações, não foram registrados comportamentos de coleta de néctar

Tabela 1. Visitantes das flores de Ipomoea asarifolia, seus respectivos totais e percentagens de visitas. Legenda: pe polinizador efetivo, po - polinizador ocasional, p - pólen.

\begin{tabular}{|c|c|c|c|c|}
\hline Ordem/Família & Espécie & Total de Visitas & $\%$ & $\begin{array}{c}\text { Eficiência } \\
\text { na polinização }\end{array}$ \\
\hline
\end{tabular}

\begin{tabular}{|c|c|c|c|c|}
\hline \multicolumn{5}{|l|}{ Hymenoptera } \\
\hline Megachilidae & Liturge huberi Ducke & 240 & 59 & pe \\
\hline Andrenidae & Acamptopoeum prinii Holm. & 88 & 22 & po \\
\hline Apidae & Diadasina riparia Ducke & 78 & 19 & po \\
\hline Total & & 406 & 100 & \\
\hline
\end{tabular}


pelos visitantes florais. Tal comportamento poderia estar relacionado com a pequena quantidade de néctar secretada pelas flores e com a altura da câmara nectarífera, que limitaria o acesso a este recurso por abelhas de língua curta, como é o caso das espécies aqui observadas. Com base no comportamento e frequiência de visitas observados, $L$. huberi foi considerada como polinizador efetivo desta Convolvulaceae, enquanto que A. prinii e $D$. riparia, polinizadores ocasionais.

Diferenças na freqüência de visitas das espécies de abelhas foram observadas em relação à coloração das flores de Ipomoea asarifolia (Tab. 2). De modo geral, observou-se que as abelhas foram atraídas pelas flores coloridas ( $97,6 \%$ do total de visitas) e raramente visitavam as flores totalmente brancas $(2,4 \%$ do total). Esta diferença nas frequiências de visitas em relação à cor da flor mostra que a coloração é um importante atrativo visual, e mudanças deste padrão podem alterar a freqüência de visitas do polinizador, o que pode refletir no processo de polinização dos tipos florais. Fato semelhante foi descrito por Ennos \& Clegg (1983) em Ipomoea purpurea, cujos polinizadores foram também atraídos pelas flores coloridas, refletindo diretamente na proporção dos tipos florais encontradas na população, uma vez que o padrão de coloração desta espécie é determinado geneticamente.

Ipomoea asarifolia é autoincompatível, formando frutos e sementes viáveis somente após a polinização cruzada (Tab. 3). Frutos apomíticos não foram observados. As maiores percentagens de frutificação foram registradas em condições naturais, sugerindo que há eficientes mecanismos de polinização. A análise estatística $\left(X^{2}\right)$ indicou que não houve diferenças significativas entre a frutificação em condições naturais e a polinização cruzada experimental $\left(X^{2}=1,92 ; \mathrm{p}=0,0421\right)$, indicando que nas flores manualmente polinizadas houve suficiente deposição de pólen para a fecundação dos óvulos, semelhante à polinização feita pelas abelhas.

Com relação aos testes de crescimento de tubo polínico, nenhuma diferença em relação à velocidade de crescimento foi observada nas regiões do estigma e estilete nos dois tratamentos. Após cinco horas, foram observados tubos polínicos na região do ovário e, após dez horas, observou-se tubos polínicos na micrópila de óvulos de flores submetidas à autopolinização, bem como nos de flores submetidas à polinização cruzada. Tais informações, juntamente com os dados obtidos com os experimentos de polinização, indicam que nesta espécie o sistema de incompatibilidade ocorre tardiamente.

Sistemas de incompatibilidade foram descritos para várias espécies de Ipomoea (Martin 1965 e 1970; Maimoni-Rodella et al. 1982; Gottsberger et al. 1988; Fidalgo 1997) e segundo Martin (1970), estes sistemas estão amplamente distribuídos no gênero, podendo também ocorrer em outros gêneros da família. Falhas de germinação dos grãos de pólen e de desenvolvimento do tubo polínico foram relatados

Tabela 2. Comparação do número total de visitas dos agentes polinizadores de Ipomoea asarifolia, em três repetições do período das 8:00 às 10:00h, entre indivíduos com flores de cores diferentes.

\begin{tabular}{lcccc}
\hline \multirow{2}{*}{$\begin{array}{c}\text { Coloração da Flor } \\
\text { (corola/mesopétala) }\end{array}$} & \multicolumn{3}{c}{ Polinizadores } & Total \\
\cline { 2 - 4 } & Liturge huberi & Acamptopoeum prinii & Diadasina riparia & 66 \\
rosa/magenta & 35 & 19 & 12 & 57 \\
branca/rosa & 29 & 14 & 14 & 03 \\
branca/branca & 02 & 01 & 00 & 126 \\
Total & 66 & 34 & 26 & 126 \\
\hline
\end{tabular}


Tabela 3. Resultados dos experimentos de polinização realizados nas flores e da germinação das sementes de Ipomoea asarifolia, na Fazenda Catalunha, Santa Maria da Boa Vista, PE. $\mathrm{N}_{1}=$ total de sementes, $\mathrm{N}_{2}=$ sementes germinadas, $\%$ - percentagem de sucesso.

\begin{tabular}{lcccc}
\hline Experimentos de Polinização & Flores & Frutos formados $(\%)$ & $\mathrm{N}_{1} / \mathrm{N}_{2}$ & $\%$ \\
\hline Condições Naturais & 30 & $23(76)$ & $15 / 14$ & 93,3 \\
Autopolinização Espontânea & 30 & $00(00)$ & - & - \\
Autopolinização Manual & 30 & $01(03)$ & $03 / 0$ & 0 \\
Apomixia & 30 & $00(00)$ & - & - \\
Polinização Cruzada & 30 & $18(60)$ & $15 / 15$ & 100 \\
\hline
\end{tabular}

em diferentes partes ao longo do gineceu (Martin 1965; Epperson \& Clegg 1987), que poderiam ser decorrentes de vários fatores, entre eles, interações pólen/estigma, variações no tempo de crescimento do tubo e aborto do embrião.

Os testes de germinação mostraram que somente as sementes obtidas em condições naturais e nos experimentos de polinização cruzada foram viáveis, com altas taxas de germinação (Tab. 3). A não germinação das sementes obtidas por autopolinização indica a ocorrência de sistemas de incompatibilidade de ação tardia, concordando com as observações de crescimento de tubo polínico.

Durante as observações verificou-se que há ocorrência de propagação vegetativa, com a formação de raízes e ramos laterais ao longo do caule, em intervalos de 10 a $30 \mathrm{~cm}$ de distância entre si. Estas ramificações, uma vez destacadas do caule, formavam novos indivíduos, garantindo a manutenção da espécie na área.

Os dados obtidos indicaram que Ipomoea asarifolia é uma espécie melitófila, de polinização cruzada, com sistema de incompatibilidade do tipo tardio (Seavey \& Bawa 1986). Quanto à polinização, esta espécie pode ser considerada como espécie oligofílica (Faegri \& van der Pijl 1980), de polinização promíscua (Percival 1969), uma vez que mais de uma abelha participa do processo de polinização e têm fácil acesso aos recursos florais. Por apresentar ampla distribuição, altas taxas de frutificação, elevado número de sementes por fruto, altas taxas de germinação e formas de propagação vegetativa, esta espécie pode ser considerada como "planta invasora ideal" (Baker 1974).

\section{Agradecimentos}

As autoras agradecem à Pesquisadora Rosângela Simão-Bianchini (Instituto de Botânica, São Paulo), pela identificação da espécie e pelas valiosas informações sobre o gênero Ipomoea; ao Prof. Dr. João M. F. Camargo (USP, Ribeirão Preto), pela identificação das abelhas, e ao CNPq, pelo auxílio financeiro.

\section{Referências bibliográficas}

Andrade-Lima, D. 1989. Plantas das Caatingas. Academia Brasileira de Ciências, Rio de Janeiro.

Austin, D. F. \& Cavalcanti, P. B. 1982. Convolvuláceas da Amazônia. Publicações Avulsas do Museu Goeldi 36: 1-134.

Baker, H. G. 1974. The evolution of weeds. Annual Review of Ecology System 5: 1-24.

Blanco, H. G. 1978. Catálogo das espécies de mato infestantes de áreas cultivadas no Brasil. Família das Campainhas (Convolvulaceae). O Biológico 44: 259-278.

Dafni, A. 1992. Pollination ecology - a practical approach. IRL Oxford University Press, Oxford.

Ennos, R. A. \& Clegg, M. T. 1983. Flower color variation in the morning glory, Ipomoea purpurea. The Journal of Heredity 74: 247-250.

Epperson, B. K. \& Clegg, M. T. 1987. First-pollination primacy and pollen selection in the morning glory, Ipomoea purpurea. Heredity 58: 5-14.

Faegri, K. \& van der Pijl, L. 1980. The principles of pollination ecology. Pergamon Press, Oxford. 
Fidalgo, A. O. 1997. Ecologia floral de duas espécies invasoras de Ipomoea (Convolvulaceae). Tese de Mestrado. Unicamp, Campinas.

Gentry, A. H. 1974. Flowering phenology and diversity in tropical Bignoniaceae. Biotropica 6: 64-68.

Gottsberger, G.; Camargo, J.M.F. \& SilberbauerGottsberger, I. 1988. A bee-pollinated tropical community: the beach dune vegetation of Ilha de São Luis, Maranhão, Brasil. Botanische Jahrbuecher fuer Systematik 109(4): 469-500.

Groth, D. 1991. Morphological characterization of seeds and seedlings of seven weed species of Convolvulaceae occuring in agricultural seeds in Brazil. Iheringia, Ser. Bot. Porto Alegre 41: 83-99.

Johansen, D. A. 1940. Plant microtechnique. McGraw-Hill Book Company, New York.

Kevan, P. G. 1978. Floral coloration, its clorimetric analysis and significance in anthecology. In: The pollination of flowers by insects. A. J. RICHARDS (ed.). London, Academic Press. p. 51-78.

Kissman, K. G. \& Groth, D. 1992. Plantas infestantes e nocivas. Basf, São Paulo. Tomo II. 798 p.

Machado, I. C. S. \& Sazima, M. 1987. Estudo comparativo da biologia floral em duas espécies invasoras: Ipomoea hederifolia e I. quamoclit (Convolvulaceae). Revista Brasileira Biologia 47(3): 425-436.

Machado I. C. S.; Santos, L. M. \& Sampaio, E. V. S. B. 1997. Phenology of caatinga species at Serra Talhada, PE, northeastern Brazil. Biotropica 29(1): 57-68.
Maimoni-Rodella, R. C. S. 1991. Biologia floral de Ipomoea aristolochiaefolia (H. B. K.) Don. (Convolvulacaea). Turrialba 41(3): 344-349.

Maimoni-Rodella, R. C. S. \& Rodella, R. A. 1992. Biologia floral de Ipomoea acuminata Roem. et Schult. (Convolvulaceae). Revista Brasileira de Botânica 15(2): 129-133.

Maimoni-Rodella, R. C. S.; Rodella, R. A.; Amaral Jr., A. \& Yanagizawa, Y. 1982. Polinização em Ipomoea cairica (L.) Sweet (Convolvulaceae). Naturalia 7: 167-172.

Martin, F. W. 1959. Staining and observing pollen tubes in the style by means of fluorescence. Stain Technology 37: 125.

Martin, F. W. 1965. Incompatibility in the sweet potato. A review. Economic Botany 19: 406-415.

Martin, F. W. 1970. Self- and interespecific incompatibility in the Convolvulaceae. Botanical Gazzette 131(2): 130-144.

Percival, M. S. 1969. Floral Biology. Pergamon Press, London.

Piedade, L. H. 1998. Biologia da polinização e reprodutiva de sete espécies de Convolvulaceae na caatinga do sertão de Pernambuco. Tese de Doutorado. Instituto de Biologia. Unicamp. 108p.

Radford, A. E.; Dickdon, W. C.; Massey, J. R. \& Bell, C. R. 1974. Vascular plant systematics. Harber and Row Publ., New York.

Seavey, S. R. \& Bawa, K. S. 1986. Late-acting selfincompatibility in angiosperms. The Botanical Review 52(2): 195-219. 